\title{
A TRADIÇÃO DA SÁTIRA MENIPEIA NOS ROMANCES CREPUSCULARES DE MACHADO DE ASSIS*
}

\author{
Wagner Martins Madeira \\ Pesquisador independente \\ São Paulo, São Paulo, Brasil
}

\begin{abstract}
Resumo: Certa crítica literária aponta Memórias póstumas de Brás Cubas como modelo de sátira menipeia na obra de Machado de Assis. O presente estudo procura demonstrar que tal procedimento satírico não foi circunstancial, pois perpassa também os dois últimos romances do escritor, Esaú e Jacó e Memorial de Aires. O conselheiro Aires - protótipo de narrador tal qual concebido no clássico ensaio de Benjamin - permite elucidar, através de sua erudição, que o recurso de citar narrativas antigas tem o propósito de subversão, ao rebaixar as práticas coevas, num Brasil que adotava as ideias liberais, embora persistisse em ser escravocrata. Os sinais, então, são trocados, o "alto" da tradição subjuga o "baixo" contemporâneo, numa demonstração de espírito tomada de segundas intenções.
\end{abstract}

Palavras-chave: Machado de Assis; Esaú e Jacó; Memorial de Aires, sátira menipeia.

\section{The Menippean satire}

in the crepuscular novels of Machado de Assis

\begin{abstract}
Certain literary criticism cites Memórias póstumas de Brás Cubas as a model of Menippean satire in the works of Machado de Assis. The present study aims to demonstrate that such satirical procedure was not circumstantial, as it is also present in the author's last two novels, Esaú e Jacó and Memorial de Aires. Conselheiro Aires - prototypical narrator, as conceived in the classic essay by Benjamin - permits us to elucidate, by means of his extensive knowledge, that citing ancient narratives presents subversion as its purpose, when lowering its contemporary practices, in Brazil, who espoused liberal ideas, even though slavery still existed. Thus exchanging the signs: "high" of tradition subdues the "low" of contemporary in a demonstration filled with spirited second intentions.
\end{abstract}

Keywords: Machado de Assis; Esaú e Jacó; Memorial de Aires; Mennippean satire.

Certa crítica literária brasileira aponta Memórias póstumas de Brás Cubas como modelo de sátira menipeia na obra de Machado de Assis. O presente estudo procura demonstrar que tal procedimento satírico não foi circunstancial, pois perpassa

\footnotetext{
* Texto inédito em publicações, apresentado na IV ICAN - International Conference on the Ancient Novel -, realizada em julho de 2008, na Fundação Gulbenkian, Lisboa, Portugal.
} 
também os dois últimos romances do escritor, Esaú e Jacó (1904) e Memorial de Aires (1908). Neles, o personagem protagonista Aires acumula as funções de autor e de narrador, repetindo o que fez Luciano de Samósata - herdeiro de Menipo de Gadara em Das narrativas verdadeiras. Na abertura desta obra de Luciano o leitor é um "ponto de referência", ${ }^{1}$ assim como o é nos romances crepusculares de Machado.

Sátira, etimologicamente "satura", revela o sentido de colheita dos contrários. No caso das intenções machadianas, a sátira é o veículo mais conveniente de expressão, para um Brasil que adotava as ideias liberais, embora persistisse em ser escravocrata. Os sinais, então, são trocados, o "alto" da tradição subjuga o "baixo" contemporâneo, numa demonstração de espírito tomada de segundas intenções.

Menipo foi pioneiro em subverter os processos normatizadores da sátira romana. Ao ridendo castigat mores contrapunha que costume não se corrige. Como se sabe, os seus textos se perderam. Afortunadamente, Varrão retoma essa via não normatizante e a transforma em dois livros: Satirorum libri e Satirorum Menipearum libri. Cícero, em sua Academica, empresta voz a Varrão, que entendia a sátira menipeia como mescla de temas filosóficos, sem dispensar o recurso do humor, a fim de que receptores menos preparados se sentissem atraídos por seu caráter lúdico. Conjuga-se, assim, o sério e o cômico, no trânsito entre o erudito e o popular, em que a sátira menipeia abre um leque de julgamentos para quem com ela se depara. Essa tradição satírica prossegue com Luciano e suas narrativas desprovidas de conselhos, que deixam o leitor livre para assumir um ponto de vista diante do ridículo apresentado. O filósofo, um mestre da retórica, vai, por conseguinte, ser o verdadeiro salvador de uma linhagem satírica cuja força é o sustentáculo de uma cultura moderna. Um processo que não se deu sem sobressaltos, haja vista a intolerância cristã para com esse tipo de sátira na Idade Média.

Coube a Erasmo retomar Luciano, em cerca de noventa narrativas. A mistura de gêneros, que já estava no antecessor, quando aliou filosofia e comédia, teve sequência em $O$ elogio da loucura, misto de ensaio e romance. Ambos primaram pela paródia, ao retomarem textos anteriores com outras intenções. Essa essência recende em Machado de Assis, quando recuperou o "aroma" da Antiguidade para fazer o diálogo com o seu mundo. Acrescente-se que o escritor brasileiro se apropriou do eflúvio

\footnotetext{
${ }^{1}$ BRANDÃO, A Invenção do Romance - Narrativa e Mimese no Romance Grego, p. 167.
} 
menipeu e o formalizou em nova flagrância, à moda de Laurence Sterne, um último elo dessa estirpe.

Enylton de Sá Rego é autor do estudo pioneiro que vinculou a sátira menipeia e Machado de Assis. O pesquisador brasileiro definiu os principais procedimentos da sátira luciânica: "mistura de gêneros, uso da paródia, extrema liberdade de imaginação, caráter não moralizante e ponto de vista distanciado". ${ }^{2}$ Características percebidas na obra madura de Machado, em que o sério se mistura ao cômico. Seus dois últimos romances têm no narrador Aires o difusor da tradição satírica menipeia.

Aires se apresenta como um protótipo de narrador tal qual foi concebido no clássico ensaio de Walter Benjamin, "O Narrador". ${ }^{3}$ O conselheiro fez muitas viagens como diplomata de carreira, é cidadão do mundo. Aposentado, tem muita coisa para contar. Sabe, contudo, que "as experiências mais fundamentais caíram na cotação". 4 Decorre daí que, pelo recurso de sua erudição, cite narrativas antigas com o propósito de subversão e de rebaixamento das práticas de seu tempo. Para Benjamin, o narrador tem que ter como qualidades a orientação para o interesse prático. Aires assim o faz no tocante à Flora, personagem de Esaú e Jacó, quando se incomoda com a indefinição dela em relação aos gêmeos Pedro e Paulo e sugere ao pai, Batista, que aceite uma comissão política, o que a afastaria da aflitiva situação em que se encontrava. Demonstra pragmatismo e toma uma decisão unilateral, já que Flora não queria se ausentar do Rio de Janeiro. Aires se mostra consciente de que no mundo seu contemporâneo está diminuindo a "imediatez da experiência". 5

Ora, não se deve olvidar que o qualificativo para Aires é "conselheiro". Destarte, sobrevêm nas atitudes do narrador o tédio e a melancolia. A esse propósito, Benjamin cunha uma bela metáfora que poderia servir de epígrafe para o narrador crepuscular de Machado: "o tédio é o pássaro onírico que choca o ovo da experiência". 6 Assim, o diplomata aposentado, o mesmo que se entedia com as controvérsias, possui as qualidades de um narrador arquetípico. Benjamin esclarece que o romance, cujos

\footnotetext{
${ }^{2}$ REGO, O calundu e a panaceia: Machado de Assis, a sátira menipeia e a tradição luciânica, p. 67.

${ }^{3}$ BENJAMIN, O Narrador - Observações sobre a obra de Nikolai Leskow, p. 57-74.

${ }^{4}$ Idem, p.57.

${ }^{5}$ Idem, p. 59.

${ }^{6}$ Idem, p. 62.
} 
primórdios remontam à Antiguidade, necessitou de centenas de anos para encontrar na burguesia em formação os elementos que serviram ao seu florescimento. Nesse sentido, é possível conjeturar que Machado escolheu um narrador com o perfil de Aires por este ter livre trânsito no mundo burguês, para que assim se tornasse crível a sua narrativa, justamente aquele mesmo que ao ser personagem foi incumbido de aconselhar os irreconciliáveis gêmeos Pedro e Paulo, a etérea e indecisa Flora, bem como o afortunado, mas sensaborão, Tristão.

Aires é um narrador que utiliza todo um instrumental satírico para rebaixar as práticas que lhe são contemporâneas. É o caso do uso da paródia, espécie de canto paralelo, de um texto que remete a outro texto. A paródia dirige-se contra personagens, tornando-as cômicas ao reivindicarem autoridade e respeito. Realiza de outra forma a degradação de algo eminente; destrói a unidade existente entre o caráter de uma personagem, tal como a conhecemos em seus discursos e atitudes, substituindo as figuras eminentes ou suas enunciações por outras, inferiores.

O narrador machadiano vai recorrer à paródia ao voltar às fontes da tradição menipeia. Na obra de Luciano há três tipos de tal procedimento literário: paródia aos gêneros e convenções da literatura passada e presente; paródia aos temas e ideias da literatura e da vida social contemporânea; paródia a textos definidos, por meio de citações literais ou quase literais, geralmente em um contexto distinto daquele do qual a passagem em questão teria sido apropriada. ${ }^{7}$ Analogamente, Machado - um leitor da obra de Luciano - faz uso desses três âmbitos paródicos da sátira menipeia ao criar o enciclopédico Aires, e seu típico learned wit, que rebaixa o estilo alto.

Machado foi muito criticado pelos seus contemporâneos por fazer uso indevido de citações. Não entendiam eles as implicações próprias do rebaixamento paródico. $\mathrm{O}$ escritor retoma a tradição luciânica, como fez Erasmo, para de uma citação truncada retirar seu aspecto de autoridade. De propósito, os seus narradores da segunda fase não são infalíveis, como se pode constatar quando no cap. XIV de Esaú e Jacó é citada por Aires uma frase supostamente de Empédocles, "a guerra é a mãe de todas as cousas". ${ }^{8} \mathrm{O}$ crédito deveria ter sido dado ao verdadeiro autor da frase, Heráclito. Não ocorre nenhuma outra razão para a troca dos nomes que não seja uma forma perversa de testar

\footnotetext{
${ }^{7}$ REGO, cit., p. 52.

${ }^{8}$ ASSIS, Obra completa, p. 967.
} 
o conhecimento do interlocutor Santos e também dos leitores em potencial. Em outro contexto o narrador altera, como lhe é típico, uma frase do padre Manuel Bernardes, de "Alonguei-me fugindo e morei na soedade", para "Alonguei-me fugindo, e morei entre a gente". ${ }^{9}$ A frase se refere ao próprio Aires, o qual queria "aplicar todos os sentidos a um mundo que podia matar o tempo, o imortal tempo". ${ }^{10}$

No que toca às frases feitas, Aires deturpa-as, rebaixando-as. Em consequência, a comicidade sobrevém, como no trato com provérbios. No capítulo LXXV, que leva o sugestivo título de "Provérbio errado", a intenção é atacar, com cáustica ironia, o personagem Nóbrega. O narrador corrige o adágio "a ocasião faz o ladrão" e desfere: "A ocasião faz o furto; o ladrão nasce feito". ${ }^{11}$ Com isso, pratica um chiste. Segundo Jean Paul, a brevidade é a alma do chiste. Desse modo, quanto mais leve a alteração em sua ordem das palavras, melhor será tecnicamente e maior a impressão de que algo diferente está sendo dito pelas mesmas palavras. ${ }^{12}$

Já no capítulo inicial de Esaú e Jacó é possível notar duas ocorrências de rebaixamento paródico. A primeira é uma citação em epígrafe: "Dico, che quando l'anima mal nata...", verso de Dante Alighieri, extraído da Divina Comédia, canto V, do "Inferno". Com esse verso, o poeta italiano quer significar aquela alma que transforma em mal o bem da vida doado por Deus. A narrativa de Aires não é nem um pouco indulgente com as coisas, divinas ou futuras, daí o rebaixamento. Por conseguinte, esperam-se dias não tão ditosos para os gêmeos.

A segunda ocorrência compara a cabocla Bárbara com a sacerdotisa Pítia, personagem de As eumênides. Na peça de Ésquilo, as predições eram caracterizadas pelo duplo sentido, cabendo aos consulentes a interpretação conforme seus próprios desejos ou temores. A associação com os gêmeos Pedro e Paulo é imediata, mas o rebaixamento vai mais além, pois as previsões da adivinha carioca não se limitam a duas escolhas, ficando num vago "cousas futuras", ${ }^{13}$ o que pode significar qualquer coisa. É o Machado que não perdoa crendices e misticismo.

\footnotetext{
${ }^{9}$ Idem, p. 989.

${ }^{10}$ Ibidem.

${ }^{11}$ Idem, p. 1045.

${ }^{12}$ FREUD, Os chistes e sua relação com o inconsciente, p. 26.

${ }^{13}$ ASSIS, cit., p. 949.
} 
No capítulo II, em que Natividade acaba de se consultar com a cabocla Bárbara, há a referência a Creso, soberano grego, último rei da Lídia, que viveu no século VI antes da era cristã. ${ }^{14}$ Igualmente consulente de uma adivinha, Pítia, que profetizou: "Se fores à guerra, destruirás um grande império". ${ }^{15}$ Feliz da vida, o monarca partiu para a luta, mas o império destruído foi o dele próprio. O rebaixamento deixa evidente o paralelo com o futuro não tão ditoso dos gêmeos. Entre outras coisas, levarão à morte a indecisa Flora, sem contar as suas incontáveis querelas, desrespeitando inclusive o juramento de paz, feito junto ao leito de morte da mãe Natividade.

O mecanismo paródico é também usado para o desmascaramento do trapaceiro que se apropriou de dignidade e autoridade, sendo então despojado destas. É o caso de Nóbrega, o irmão das almas que surrupia a esmola dada por Natividade, parodiado com um trecho da peça Britannicus, de Racine: "Ni cet excès d'honneur, ni cette indignité". ${ }^{16}$

A França aparece de novo, num comentário literário em que se compara o Candido de Voltaire e o Cacambo de Basílio da Gama, obviamente valorizando-se aquele e depreciando-se este. ${ }^{17} \mathrm{O}$ propósito do narrador é ironizar o otimismo ingênuo reinante no período conhecido como encilhamento, de grande agitação nas Bolsas de Valores e de atividade econômica intensa. Os investidores desconhecem que as estradas de ferro, fábricas, minas, estaleiros não sairão do papel. Não se deve esquecer que o personagem Santos enriquece justamente com este tipo de negócio. A sátira não se limita aos capitalistas, estende-se à sociedade arrivista, através de imagens literáriomitológicas que incluem Homero, Juno, Minerva, Ílion - associados a "tudo de ouro incorruptível". ${ }^{18}$ Portanto, o trecho apresenta dois rebaixamentos: do idioma português em relação ao idioma francês e da corrupção da vida brasileira contrastada com a supostamente impoluta cultura grega clássica.

$\mathrm{O}$ capítulo XV também se presta à ocorrência do rebaixamento. A começar pelo nome, "Teste David cum Sibila", o qual talvez queira dizer que tanto a profecia

\footnotetext{
${ }^{14}$ MADEIRA, Machado de Assis: homem lúdico, p. 96.

${ }^{15}$ Ibidem.

${ }^{16}$ Idem, p. 99.

${ }^{17}$ ASSIS, cit., p. 1042.

${ }^{18}$ Ibidem.
} 
religiosa (Davi e, por extensão, o personagem Plácido) como a profecia pagã (Sibila e a cabocla do Castelo) cheguem à mesma conclusão do destino humano. Assim, os nomes "Pedro" e "Paulo" podem ser predestinados. A conclusão, formulada por Plácido, para os olhos de Santos, "ordinariamente sem expressão", ${ }^{19}$ ganharam vida com a hipótese megalômana de os filhos serem reencarnação dos apóstolos que lhes dão nomes. A sátira é evidente e não requer maiores comentários.

Impagável é o exemplo no qual Natividade é comparada às referências geográfico-mitológicas de Os Lusíadas (cabo das Tormentas, cabo da Boa Esperança, Adamastor, Tétis) que remetem às suas negativas aos pretendentes João de Melo e, "ainda pior", a Aires. ${ }^{20} E$ uma forma de chiste porque faz uma analogia degradante que justapõe algo de alta categoria, abstrato, com algo muito concreto e de um gênero baixo. No mesmo diapasão, o rebaixamento continua em digressão do narrador, comparando histórias infantis dos gêmeos com o Decameron, ${ }^{21}$ como se sabe obra licenciosa e galhofeira de Boccaccio.

A sátira do rebaixamento continua com a citação de Amós, profeta do antigo testamento, que se refere desdenhosamente às mulheres de Samaria como "vacas gordas". O republicano Paulo se apropria da imagem para se referir ao regime monarquista. ${ }^{22}$ Satírico também é o capítulo seguinte, no qual o narrador trabalha com as desproporções. Aires cita a Ilíada e a Odisseia para definir os irmãos. Eles, por sua vez, preferem o rebaixamento, acusam-se em bom e sonoro português: "velhaco", "furioso". São contidos pelo diplomata: "em grego, meninos, em grego e em verso, que é melhor que nossa língua e a prosa de nosso tempo". ${ }^{23}$

A sátira do narrador às vezes é corrosiva, por exemplo, com D. Cláudia. O capítulo LV tem como título "A mulher é a desolação do homem", frase que se repete no intercurso do texto, atribuída ao filósofo socialista Proudhon. ${ }^{24}$ Aí o narrador distorce o contexto, pois a frase original referia-se às cortesãs e às concubinas. A mudança de tom ocorre novamente com um Aires assumidamente diplomático, lendo

\footnotetext{
${ }^{19}$ Idem, p. 969.

${ }^{20}$ Idem, p. 974.

${ }^{21}$ Idem, p. 973.

${ }^{22}$ Idem, p. 1002.

${ }^{23}$ Ibidem.

${ }^{24}$ Idem, p. 1019.
} 
Xenofonte, sobre os governos que são derrubados: "o homem é difícil de governar". ${ }^{25} \mathrm{O}$ momento poderia ser trágico, sangrento, pois o regime passava da monarquia para a república. O conselheiro, porém, atenua as notícias de morte, sabendo-as exageradas pelo vulgo, "cresce de dois terços". ${ }^{26}$ Supunha, a seu ver, apenas uma mudança de gabinete, de pessoal.

O capítulo LXXII traz a desproporção que leva ao rebaixamento. Nele o fisiológico Batista se encontra arrependido por não ter publicado um manifesto político, que citava a célebre frase da escritora e ativista política francesa Madame Roland, a caminho da guilhotina: "Ó liberdade, quantos crimes em teu nome". ${ }^{27}$ Nesse caso, temos a exageração paródica, que instaura o nonsense cômico e é uma forma de chiste, espécie de jogo desenvolvido.

O narrador-personagem propõe uma solução para a indefinição da ligação com Flora e conclama os gêmeos a desfazerem o nó górdio: "Você, Pedro, tentará primeiro desatá-lo; se ele não puder, Paulo, você pegue a espada de Alexandre, e dê-lhe o golpe". ${ }^{28} \mathrm{O}$ episódio provém da lenda envolvendo Alexandre, o Grande, que dirigiu-se ao templo de Zeus para desatar o referido nó. É como se Aires se divertisse com o jogo do rebaixamento. Contudo, por vezes o clima é soturno: Flora é instada pelo narrador a citar Goethe: "Ai, duas almas nos meus seios moram", ${ }^{29}$ prenúncio de mau agouro, condição fáustica que se confirma quando o diabo lhe aparece, agora como Mefistófeles. Por ocasião do enterro da personagem, o tédio dos coveiros é comparado aos trovadores de Hamlet. ${ }^{30} \mathrm{O}$ tom paródico é reforçado na alusão à Divina Comédia, só que os valores são invertidos. Enquanto no texto de Dante Beatriz guia o poeta pela mão em visita ao paraíso, em Esaú e Jacó Flora desce dos céus para ouvir os gêmeos perpetuamente, "uma Beatriz para dois" ${ }^{31}$ é a expressão cunhada pelo narrador, e que dá título também ao capítulo CXIII, contundente exemplo de rebaixamento pela lubricidade que encerra.

\footnotetext{
${ }^{25}$ Idem, p. 1026.

${ }^{26}$ Ibidem.

${ }^{27}$ Idem, p. 1040.

${ }^{28}$ Idem, p. 1060.

${ }^{29}$ Idem, p. 1050.

${ }^{30}$ Idem, p. 1080-1081.

${ }^{31}$ Idem, p. 1085.
} 
Quanto ao romance Memorial de Aires, igualmente o rebaixamento paródico se manifesta. Um primeiro exemplo da anotação do diário do conselheiro, datada de 25 de janeiro de 1888, se dá quando Aires, contemplando Fidélia, lembra-se de célebre verso de Shelley: "I can give not what men call love". Ao traduzi-lo para o leitor, o narradorprotagonista não perde a chance de uma emenda prosaica: "Eu não posso dar o que os homens chamam amor... e é pena!". ${ }^{32}$ É a sátira do rebaixamento, que ao modificar um autor citado permite o flerte com a tradição luciânica. Para reforçar o efeito cômico, o referido verso sobrepaira inúmeras vezes no decorrer do romance, circulando como um bordão autoparódico à incapacidade de sedução do velho narrador-personagem.

$\mathrm{Na}$ anotação do dia 24 de agosto de 1888 , a propósito de uma furtiva lágrima de Fidélia, Aires cita o Eclesiastes, em tom paródico e de rebaixamento: "Já dizia ele que nada era novo debaixo do sol, e se o não era então, não o foi nem será nunca mais. Tudo é assim contraditório e vago também". ${ }^{33}$ O tema volta à baila no dia 14 de setembro, ironizando a pretensão de Osório em se casar com Fidélia: "Tudo é possível debaixo do sol - e a mesma cousa sucederá acima dele - Deus sabe". ${ }^{34}$ Em 13 de março de 1889, há uma última recorrência, revestida e modificada, para não dizer deturpada, em uma metáfora sobre o amor enunciada por Aires: "O drama é de todos os dias e de todas as formas, e novo como o sol, que também é velho". 35

$\mathrm{Na}$ anotação do diário de 5 de fevereiro de 1888, a condição existencial do narrador é retratada de forma direta, autorrebaixada: "Nada há pior que gente vadia - ou aposentada, que é a mesma cousa". ${ }^{36}$ No dia 10 de fevereiro, há um admirável diálogo entre Aires e sua irmã, que se revela um jogo de desproporções tipicamente machadiano. Rita afirma em tom de questionamento:

- Agora diga se ela é viúva que se case.

- Com qualquer, não; pelo menos, é difícil; mas, um sujeito fresco - continuei enfunando-me e rindo.

- Você ainda pensa...?

\footnotetext{
${ }^{32}$ Idem, p. 1104.

${ }^{33}$ Idem, p. 1141.

${ }^{34}$ Idem, p. 1149.

${ }^{35}$ Idem, p. 1187.

${ }^{36}$ Idem, p. 1111.
} 
- Eu, mana? Eu penso no seu jantar, que há de estar delicioso. O que me fica da história é que essa moça, além de bonita, é teimosa; mas a sua sopa vale para mim todas as noções estéticas e morais deste mundo e do outro . ${ }^{37}$

Como se vê, um trecho em que o alto, o sentimento, anda de par com o baixo, o apetite, sátira literalmente mordente. $\mathrm{Na}$ anotação de 12 de abril, há um comentário de Aires de sabor metalinguístico, cético em toda a linha, a respeito de uma sua conversa com Santa Pia, pai de Fidélia:

Está claro que lhe não falei da filha, mas confesso que se pudesse diria mal dela, com o fim secreto de acender mais o ódio - e tornar impossível a reconciliação. Deste modo ela não iria daqui para a fazenda, e eu não perderia o meu objeto de estudo. Isto sim, papel amigo, isto podes aceitar, porque é a verdade íntima e pura e ninguém nos lê. Se alguém lesse achar-me-ia mau, e não se perde nada em parecer mau; ganha-se quase tanto como em sê-lo. ${ }^{38}$

No dia 11 de fevereiro, a respeito da onomástica da família de Fidélia, de título nobiliário Santa Pia, Aires faz o peculiar jogo das desproporções, do alto e do baixo, ao aludir a Dante: "Ricorditi di me, chi son la Pia". ${ }^{39}$

No apontamento de 10 de abril, o barão de Santa Pia redige com o irmão Campos carta de alforria para os escravos de sua fazenda, antecipando-se por mera oposição ao governo. O comentário que segue do fazendeiro vale por tratados de história: - "Estou certo que poucos deles deixarão a fazenda; a maior parte ficará comigo, ganhando o salário que lhes vou marcar, e alguns até sem nada - pelo gosto de morrer onde nasceram". ${ }^{40}$ No registro de 13 de maio, Aires não só não participa dos folguedos pela Abolição, como usa de sátira, de cunho paródico, avesso ao tom celebratório, no trecho em que o sublime da poesia anda de mãos dadas com o profano do tráfico de escravos:

A poesia falará dela, particularmente naqueles versos de Heine, em que o nosso nome está perpétuo. Neles conta o capitão do navio

\footnotetext{
${ }^{37}$ Idem, p. 1113.

${ }^{38}$ Idem, p. 1117.

${ }^{39}$ Idem, p. 1113.

${ }^{40}$ Idem, p. 1116.
} 
negreiro haver deixado trezentos negros no Rio de Janeiro, onde "a Casa Gonçalves Pereira" lhe pagou cem ducados por peça. Não foi a rima ou a sua má pronúncia que o levou a isso. Também não temos ducados, mas aí foi o vendedor que trocou na sua língua o dinheiro do comprador ${ }^{41}$

Como se percebe, pelos exemplos citados, Aires é um privilegiado espectador da história brasileira. Em Esaú e Jacó pôde constatar a falta de empolgação para com a Proclamação da República, no antológico episódio da tabuleta de Custódio. No Memorial de Aires, os comentários do dia 14 de maio revelam igual indiferença. Aires felicita o alegre casal Aguiar e julga que a causa de tal felicidade seria a Abolição da Escravatura. Na verdade, a alegria advinha de motivo prosaico, uma carta recebida do filho postiço Tristão. ${ }^{42}$

Assim, como é próprio da obra madura machadiana, na política brasileira o geral perde para o particular, o alto é derrotado pelo baixo. Como resultado, a desproporção se afigura invariavelmente cômica. $\mathrm{Na}$ anotação de 17 de maio, o quadro melancólico para com a política brasileira se intensifica. Há como que um desencanto, uma espécie de ressaca pós-Abolição, em que o sentimento de misantropia do narrador encontra contraponto no criado José, não por acaso um negro. O narrador dissimula, acusa a sua própria velhice, mas o que fica é uma sub-reptícia mensagem de tédio e melancolia, que extrapola o indivíduo e ganha o âmbito da sociedade:

Vou ficar em casa uns quatro ou cinco dias, não para descansar, porque eu não faço nada, mas para não ver nem ouvir ninguém, a não ser o meu criado José. Este mesmo, se cumprir, mandá-lo-ei à Tijuca, a ver se eu lá estou. Já acho mais quem me aborreça do que quem me agrade, e creio que esta proporção não é obra dos outros, é só minha exclusivamente. Velhice esfalfa. ${ }^{43}$

São intervenções dissimuladas como essas que fizeram por muito tempo a crítica ingenuamente considerar a obra de Machado conservadora e alienada. Nada mais enganoso, pois há na subterrânea camada discursiva uma atilada mensagem satírica para

\footnotetext{
${ }^{41}$ Idem, p. 1118.

${ }^{42}$ Idem, p. 1118-1119.

${ }^{43}$ Idem, p. 1119.
} 
com o comportamento preconceituoso da elite brasileira, aqui representada por Aires, na depressão pós-abolição dos escravos.

No registro de 25 de julho, uma reflexão do conselheiro permite estabelecer similaridade entre o que escreve em seu diário e o prazer de seus leitores, trecho de pronunciada metalinguagem, não isenta de rebaixamento quanto aos destinatários:

As cartas velhas são boas, mas estando eu velho também, e não tendo a quem deixar as que me restam, o melhor é rasgá-las. Fiquei só com oito ou dez para reler algum dia e dar-lhes o mesmo fim. Nenhuma delas vale uma só das de Plínio, mas a todas posso aplicar o que ele escrevia a Apolinário: "teremos ambos o mesmo gosto, tu em ler o que digo, e eu em dizê-lo". Os meus Apolinários estão mortos ou velhos; as Apolinárias também. ${ }^{44}$

$\mathrm{Na}$ tradição luciânica, a imaginação narrativa tem papel decisivo. Nas observações do Memorial de Aires, que compreendem de 24 de maio a 09 de junho de 1888, os laivos românticos de Aires voam alto ao sonhar um diálogo com a viúva Fidélia, em que questões da história são parodiadas. Completam o quadro idílico as estações do ano, primavera e inverno, que servem de metáfora a uma possível aproximação entre Fidélia e o pretendente Osório, mordido de amores por ela: dos "gelos às flores". ${ }^{45}$ Imaginação de rédeas soltas, sátira cortante, concluída com a recusa da personagem, ao que Aires não perde a chance de comparar às três vezes que Pedro negou a Cristo. ${ }^{46}$ Novamente o alto e o baixo, o sagrado e o profano, tratado com impagável e cruel comicidade. No balanço do arrastão satírico-narrativo do episódio são levados de roldão, a um só tempo, o romantismo, a história, a religião. Na mesma linha, no dia 27 de junho, Aires depõe sobre suas práticas religiosas: "A segunda confissão foi por ocasião de casar. Daí em diante não fui mais que virtudes". ${ }^{47} \mathrm{Ou}$ seja, nunca mais confessou, típica manifestação satírica, como reza a tradição luciânica.

O rebaixamento de natureza religiosa prossegue por ocasião da missa de sétimo dia do barão de Santa Pia, em que alguns ausentes pediram aos participantes a inclusão

\footnotetext{
${ }^{44}$ Idem, p. 1133.

${ }^{45}$ Idem, p. 1124.

${ }^{46}$ Ibidem.

${ }^{47}$ Idem, p. 1130.
} 
de seus nomes no livro de presentes. ${ }^{48}$ Suma machadiana, tanto para Esaú e Jacó e Memorial de Aires: assim como a política brasileira, o rito religioso não empolga. É o que se constata no apontamento de $1^{\circ}$ de agosto, em que a sátira assume foros de metalinguagem, em forma de rebaixamento que contempla a um só tempo o familiar, o político e o religioso, ao não poupar um sonho de Fidélia que reconciliaria os finados seu pai e seu marido.

Aires conjectura, mas não enuncia uma "facécia": "A reconciliação eterna, entre dous adversários eleitorais, deve ser exatamente um castigo infinito. Não conheço igual na Divina Comédia. Deus quando quer ser Dante é maior que Dante". ${ }^{49}$ Oportunidade para um desdobramento, em 4 de setembro, ao continuar a sátira para com Fidélia: "Daqui a cinco anos, ela mandará transferir os ossos do pai para a cova do marido, e os conciliará na terra uma vez que a eternidade os conciliou já". ${ }^{50}$ Percebe-se por estas duas passagens o quanto é ladino o narrador Aires, legítimo sucessor da tradição luciânica, ao jogar com a percepção de seus leitores, pois a eternidade para os dois inimigos terrenos se transformou de "castigo infinito" em conciliação. Se o leitor se mostrar desatento perde o tom satírico e é trapaceado pelos blefes do narrador finório.

Atenção que aos leitores também não deve faltar quanto aos comentários do narrador sobre o código romanesco. No diário do Memorial, em 15 de junho de 1888, avulta a questão da verossimilhança:

Há na vida simetrias inesperadas. A moléstia do pai de Osório chamou o filho ao Recife, a do pai de Fidélia chama a filha à Paraíba do Sul. Se isto fosse novela algum crítico tacharia de inverossímil o acordo de fatos, mas já lá dizia o poeta que a verdade pode ser às vezes inverossímil . ${ }^{51}$

Machado e Aires negam a onisciência perfeita. O Aires autor, em particular, frequentemente admite frustração e carência de penetração em olhar firme para os

\footnotetext{
${ }^{48}$ Ibidem.

${ }^{49}$ Idem, p. 1135.

${ }^{50}$ Idem, p. 1145.

${ }^{51}$ Idem, p. 1126.
} 
personagens de seu diário - até mesmo para si mesmo, o único que os pensamentos pressupõe-se deveriam ser conhecidos.

No cap. LX de Esaú e Jacó, ele escreveu: "Não juro que assim fosse, porque o dia já vai longe, e as pessoas não eram conhecidas. O próprio Aires, se tal cousa suspeitou, não a disse a ninguém, também não afiou o ouvido para alcançar o resto". ${ }^{52}$ Tal procedimento é peculiar da sátira luciânica, no sentido de não moralizar, chegando mesmo a ridicularizar a sua própria posição. Assim sendo, a linguagem se revela ambígua, dessacralizando verdades absolutas e sistemas filosóficos, ao solapar e relativizar suas próprias afirmações. A exemplo de Luciano, que "pertence a um mundo que perdeu há muito toda e qualquer inocência", ${ }^{53}$ Machado criou um narrador astuto e matreiro, típico da tradição menipeia, tributário de antecessores criados por Erasmo, Burton e Sterne.

Ao se fazer um balanço da atuação do Aires narrador, nota-se que é um observador distanciado. Pratica o chamado kataskopos, isto é, vê o mundo do alto, a exemplo do que ocorre nas narrativas de Luciano de Samósata. O ponto de vista distanciado do narrador machadiano o afasta dos gêneros literários vigentes na literatura brasileira, renovando-os. Ao potencializar a escritura imaginativa, o narrador relativiza o conceito de verossimilhança, não se baseando numa poética da mimesis, aristotélica, mas sim numa poética fundada na paródia, ao mesmo tempo não moralizante, imaginativa, subversiva e que a tudo rebaixa. Enfim, pelos procedimentos satíricos apontados nos romances Esaú e Jacó e Memorial de Aires, Machado de Assis pode ser considerado um legítimo herdeiro da tradição menipeia.

\section{Referências:}

ASSIS, Machado de. Obra completa - v. 1. Rio de Janeiro: Nova Aguilar, 1979.

BENJAMIN, Walter. O Narrador - Observações sobre a obra de Nikolai Leskow. In: Os Pensadores - v. Escola de Frankfurt, 2. ed., São Paulo: Nova Cultural, 1983. p. 5774.

\footnotetext{
${ }^{52}$ Idem, p. 1025.

${ }^{53}$ BRANDÃO, cit., p. 213.
} 
BRANDÃO, Jacyntho Lins. A Invenção do Romance - Narrativa e Mimese no Romance Grego. Brasília: UNB, 2005.

FREUD, Sigmund. Os chistes e sua relação com o inconsciente. Rio de Janeiro : Imago, 1977.

MADEIRA, Wagner Martins. Machado de Assis : homem lúdico. Uma leitura de Esaú e Jacó. São Paulo: Annablume, 2001.

REGO, Enylton de Sá. O calundu e a panaceia: Machado de Assis, a sátira menipeia e a tradição luciânica. Rio de Janeiro: Forense, 1989.

Wagner Martins Madeira realizou sua formação acadêmica na FFLCH - USP: graduação (1982), Letras Clássicas e Vernáculas; mestrado (1999) e doutorado (2003), em Letras, Literatura Brasileira. Tem pesquisado os seguintes temas: Machado de Assis; Teatro brasileiro: Martins Pena e Oduvaldo Vianna; Prosa contemporânea: Ronaldo Correia de Brito. A dissertação de mestrado Machado de Assis: homem-lúdico. Uma leitura de Esaú e Jacó foi publicada em 2001, pela Annablume. Realizou pósdoutoramento em Literatura Brasileira sobre a obra de Ronaldo Correia de Brito, na UNESP - Assis, de 2011 a 2013. E-mail: <wmmadeira@ig.com.br>

Recebido: 08.03.2014

Aprovado: 31.03.2014 